\title{
Pelatihan Penyusunan Rencana Bisnis untuk Badan Usaha Milik Desa di Kecamatan Lumbir
}

\section{Business Plan Preparation Training for Village-Owned Enterprises in Lumbir Subdistrict}

\author{
${ }^{1 *}$ Slamet Rosyadi, ${ }^{2)}$ Wita Ramadhanti, ${ }^{3)}$ Denok Kurniasih, ${ }^{4)}$ Ayusia Sabhita Kusuma, \\ ${ }^{5}$ Paulus Israwan Setyoko, ${ }^{6}$ Zaula Rizqi Atika \\ ${ }^{1,3,5)}$ Program Studi Administrasi Publik, Fakultas Ilmu Sosial dan Ilmu Politik \\ ${ }^{2)}$ Program Studi Akuntansi, Fakultas Ekonomi dan Bisnis \\ ${ }^{4)}$ Program Studi Hubungan Internasional, Fakultas Ilmu Sosial dan Ilmu Politik \\ Universitas Jenderal Soedirman \\ Jl. HR Bunyamin No 99 Grendeng Purwokerto 53132 \\ ${ }^{6}$ Program Studi Administrasi Publik, Universitas Nahdlatul Ulama, Purwokerto \\ Jl. Sultan Agung No. 42, Windusara, Karangklesem, Purwokerto \\ *email: slamet.rosyadi@unsoed.ac.id
}

DOI:

10.30595/jppm.v5i1.6829

\begin{abstract}
ABSTRAK
Badan Usaha Milik Desa (BUMDes) dibentuk dalam rangka implementasi Undang-undang nomor 6 Tahun 2014 tentang Desa. Namun demikian perkembangan BUMDES masih belum optimal sebagai penyumbang Pendapatan Asli Desa (PADes). Berdasarkan hal tersebut, dalam kegiatan pengabdian ini dilakukan pelatihan pembuatan rencana bisnis kepada BUMDes di Kecamatan Lumbir, Kabupaten Banyumas. Sebelum pelatihan, dilakukan focus group discussion dan survey untuk memetakan permasalahan dan kebutuhan peningkatan kapasitas para pengelola BUMDes. Pelatihan dilakukan dengan metode ceramah dari praktisi dan tim pengabdi serta praktik pembuatan rencana bisnis. Pelatihan diikuti oleh 16 orang dari 10 BUMDes. Pasca pelatihan, tim pengelola BUMDes telah berhasil membuat rencana bisnis. Pengabdian ini penting sebagai dasar pengajuan unit usaha BUMDes sebagai badan hukum formal.
\end{abstract}

Histori Artikel:

Diajukan:

22/02/2020

Diterima:

$29 / 03 / 2021$

Diterbitkan:

30/03/2021

Kata kunci: Badan Usaha Milik Desa; Rencana Bisnis; Keuangan; Pelatihan

\begin{abstract}
Village-owned Enterprises (BUMDes) was formed in the context of implementing Law number 6 of 2014 on Villages. However, the development of BUMDes is still not optimal as a contributor to Village's Initial Revenues (PADes). Based on this problem, this community service conducted training on business plan making for BUMDes in Lumbir Subdistrict, Banyumas Regency. Before the training, focus group discussion and survey were done to map out the problems and needs for capacity enhancement for BUMDES managers. The training was conducted using lecture methods from practitioners and the community service team, as well as the practice of making business plans. The training was attended by 16 people from 10 BUMDes. After training, the BUMDes management team has succeeded in making a business plan. This community service activity is important as a basis for submitting BUMDES business units as formal legal entities.
\end{abstract}

Keywords: Village-Owned Enterprises; Business Plan; Finance; Training 


\section{PENDAHULUAN}

Sebagai bagian dari implementasi UU No 6 Tahun 2014 tentang Desa, Badan Usaha Milik Desa (BUMDes) dibentuk untuk meningkatkan pengelolaan sumber daya di desa. Namun demikian, dalam praktiknya 2.188 BUMDes tidak beroperasi sesuai harapan (Tempo, 2019).

Hasil penelitian juga menunjukkan bahwa kegagalan pengelolaan BUMDes disebabkan oleh ketidakmampuan pengelola BUMDes dalam memberikan nilai tambah kepada pemerintah desa (Kurniasih \& Wijaya, 2017). Penelitian lainnya melaporkan bahwa kinerja BUMDes sangat ditentukan oleh keahlian, pelatihan dan pengalaman (Sofyani, Atmaja, dan Rezki, 2019).

Salah satu titik kelemahan BUMDes adalah absennya kepemilikan dokumen rencana bisnis. Sebagai sebuah lembaga bisnis, BUMDes idealnya telah memiliki dokumen yang berisi alasan pendirian dan berbagai strategi pencapaian tujuan pendirian BUMDes. Ironisnya, tidak semua BUMDes memiliki rencana bisnis. Akibatnya, BUMDes terkendala mendapatkan penyertaan modal dari dana desa (Rosyadi, 2019).

Lemahnya kapasitas BUMDEs tersebut menjadi alasan penting untuk memberikan pelatihan tentang penyusunan rencana bisnis. Dengan pelatihan tersebut dapat menjadi solusi bagi BUMDes untuk mengatasi persoalan tata kelolanya. Kepercayaan pemerintah desa dan masyarakat akan meningkat jika BUMDes diperkuat dengan adanya dokumen rencana bisnis.

Tujuan kegiatan ini adalah untuk meningkatkan pengetahuan pengelola BUMDes dalam menyusun rencana bisnis sehingga BUMDes dapat dikelola secara profesional dan akuntabel.

\section{METODE}

Kegiatan ini menerapkan metode pelatihan. Tema pelatihan yang disepakati bersama dengan pengelola BUMDEs adalah penyusunan dokumen rencana bisnis. Kesepakatan tema pelatihan penting dilakukan sebelum pelatihan diselenggarakan. Melalui diskusi kelompok dengan semua pengelola BUMDes di Kecamatan Lumbir bersama dengan Camat Lumbir teridentifikasi kebutuhan pelatihan penyusunan dokumen rencana binsis.

Tahapan pelatihan ini dalam kegiatan pengabdian ini mencakup:

1. Diskusi Kelompok Terfokus.

Pada tahap awal ini, tim pengabdi dan pengelola BUMDes dari 10 desa di Kecamatan Lumbir berdiskusi untuk menemukan kebutuhan pelatihan. Berdasarkan hasil diskusi ini, disepekati pelatihan penyusunan rencana bisnis.

2. Penyusunan Materi Pelatihan.

Tim pengabdi bersama praktisi bisnis yang berpengalaman mendampingi Usaha Kecil Menengah (UKM) merumuskan kisi-kisi materi pelatihan. Berdasarkan hasil diskusi, diidentifikasi ruang lingkup materi pelatihan sebagai berikut: (1) penyusunan visi misi BUMDes; (2) pelaporan keuangan praktis; (3) pemetaan produk/jasa; dan (4) strategi pemasaran produk/jasa.

3. Pelatihan penyusunan rencana bisnis.

Untuk mengukur tingkat keberhasilan pelatihan, kuesioner dibagikan kepada peserta sebelum dan sesudah pelaksanaan pelatihan. Peserta yang terlibat berjumlah 16 orang dari 10 BUMDes di Kecamatan Lumbir.

\section{HASIL DAN PEMBAHASAN}

Terdapat 10 BUMDes di Kecamatan Lumbir Kabupaten Banyumas Jawa Tengah. Tujuh puluh persen BUMDes telah berdiri selama 1-5 tahun, berarti masih tergolong baru. Ada 60 persen BUMDes yang memiliki karyawan kurang dari 5 orang, berarti hampir keseluruhan merupakan usaha mikro. Modal BUMDes sebagian besar kurang dari Rp 50 juta, hanya 2 BUMDes yang memiliki modal lebih dari itu. Sumber modal umumnya dari pemerintah desa. Hal ini menunjukkan bahwa kondisi BUMDes masih baru, mikro, dan bergantung pada pemerintah Desa. 
Tabel 1. Profil BUMDes

\begin{tabular}{ccc}
\hline Profil & Kategori & Jumlah \\
\hline Umur & $<1$ & 2 \\
BUMDes & $1-5$ & 7 \\
(tahun) & $>5$ & 1 \\
& Total & $\mathbf{1 0}$ \\
Jumlah & $<5$ & 6 \\
karyawan & $5-10$ & 2 \\
(orang) & $>10$ & 2 \\
& Total & $\mathbf{1 0}$ \\
Modal awal & $<25$ juta & 2 \\
(Rp.) & $25-50$ juta & 8 \\
& $>50$ juta & 2 \\
& Total & $\mathbf{1 0}$ \\
\hline
\end{tabular}

Sumber: Data diolah

Satu BUMDes umumnya memiliki beberapa unit usaha. Sayangnya, berdasarkan diskusi belum ada satupun yang memiliki badan hukum resmi. Jenis usaha yang banyak dimiliki adalah usaha simpan pinjam yaitu sebanyak 8 BUMDes memiliki unit usaha ini. Unit usaha simpan pinjam ini umumnya melanjutkan Program Nasional Pemberdayaan Masyarakat (PNPM) Mandiri Pedesaan dan atau Simpan Pinjam Perempuan (SPP) dari pemerintah pusat. Pelaksanaan PNPM Mandiri Pedesaan berada di bawah binaan Direktorat Jenderal Pemberdayaan Masyarakat dan Desa (PMD), Kementerian Dalam Negeri. Program ini didukung dengan pembiayaan yang berasal dari alokasi Anggaran Pendapatan dan Belanja Negara (APBN), alokasi Anggaran Pendapatan dan Belanja Daerah (APBD), dana pinjaman/hibah luar negeri dari sejumlah lembaga pemberi bantuan dibawah koordinasi Bank Dunia (wikipedia, 2018). Program ini berakhir dan dilanjutkan pengelolaannya kepada Desa sejak diberlakukannya Undangundang Nomor 6 Tahun 2014 tentang Desa.

Bidang usaha selanjutnya yang populer adalah air bersih. Empat BUMDes memiliki unit usaha produksi air bersih. Hal ini merupakan hasil dari Program Nasional Penyediaan Air Minum dan Sanitasi Berbasis Masyarakat (PAMSIMAS). Kelompok Kerja Air Minum dan Penyehatan Lingkungan (Pokja AMPL) Nasional merupakan sebuah lembaga adhoc yang dibentuk pada tahun 1997 sebagai wadah atau forum komunikasi dan koordinasi agar pembangunan air minum dan sanitasi berjalan lebih baik. terdiri dari 8 Kementerian yaitu Kementerian PPN/Bappenas, Kementerian Pekerjaan Umum, Kementerian Dalam Negeri, Kementerian Kesehatan, Kementerian Lingkungan Hidup, Kementerian Keuangan, Kementerian Pendidikan dan Kebudayaan, dan Badan Pusat Statistik.

Selain simpan pinjam dan air bersih yang merupakan lanjutan dari program nasional, beberapa BUMDes juga memiliki unit usaha atas inisiatif sendiri. Unit usaha lain yaitu sewa molen, bus sekolah, posyantek, perdagangan, dan produksi. Ada juga yang memiliki usaha lain-lain seperti broker dan usaha bersama. Jika satu BUMDes sukses dengan 1 jenis unit usaha, BUMDes kelurahan lain akan membuat unit usaha yang sama. Hal ini menyebabkan meningkatnya kompetisi sehingga kurang berkembang. Hal ini juga menunjukkan kurangnya kreatifitas pengelola BUMDes dalam menciptakan unit usaha baru. Kurangnya perencanaan dan inisitif usaha ini menjadi masalah utama bagi BUMDes yang harus diselesaikan.

Tabel 2. Permasalahan BUMDes

\begin{tabular}{llc}
\hline \multicolumn{2}{c}{ Permasalahan } & Jumlah \\
\hline Beroperasi & Ya & 7 \\
sepanjang & Tidak & 3 \\
tahun & Total & $\mathbf{1 0}$ \\
Menyusun & Ya & 5 \\
laporan & Tidak & 5 \\
keuangan & Total & $\mathbf{1 0}$ \\
Masalah & Politis: pilkades & 3 \\
lain-lain & atau & \\
& ketidaksepakatan & \\
& dengan desa & \\
& Masalah & 3 \\
& pengelolaan & \\
& Kurang SDM & 2 \\
& Konsumen & 1 \\
& bermasalah & 1 \\
& Lain-lain & $\mathbf{1 0}$ \\
\hline
\end{tabular}

Sumber: Data diolah 
Selain masalah perencanaan usaha, ada beberapa permasalahan BUMDes yang harus diatasi segera. Pertama, separuh BUMDes merasa belum dapat menyusun laporan keuangan dengan baik. Kedua, beberapa BUMDes merasa bahwa unit usaha BUMDes tidak dapat berjalan sepanjang tahun, misalnya PAMSIMAS hanya berjalan 6 bulan saat musim hujan, sedangkan pada musim kemarau, airnya turut kering sehingga layanannya terhenti. Masalah lain yang juga ditemukan antara lain adanya masalah politis pemilihan kepala desa dengan perangkat desa. Pergantian kepala atau perangkat desa biasanya berakibat pada pergantian pengelola BUMDes. Akibatnya, pengelolaan BUMDes tidak optimal. Masalah lainnya antara lain kurangnya Sumber Daya Manusia yang berusia muda dan berpendidikan tinggi. Hal ini dapat dilihat dari peserta pelatihan yang lulusan S1 hanya 2 orang dengan 3 orang yang berusia di bawah 30 tahun.

Pelatihan disampaikan oleh tim pengabdi berkolaborasi dengan praktisi bisnis. Tim pengabdi menyampaian materi mengenai penyusunan visi-misi organisasi dan teknik penyusunan laporan keuangan praktis. Praktisi bisnis menyampaikan materi mengenai pemetaan produk/jasa dan strategi pemasaran. Kolaborasi ini dilakukan sehingga peserta pelatihan mendapatkan gambaran yang konkrit tentang penyusunan rencana bisnis.

Penelitian mengenai penguatan kapasitas usaha kecil telah banyak dilakukan. Studi yang dilakukan Bovens (2007), Dixon, Ritchi \& Siwale (2006), Lodhia \& Burritt (2004) terhadap praktek akuntabilitas keuangan sektor publik menyimpulkan bahwa meskipun mekanisme akuntabilitas telah dibangun dengan baik, namun mekanisme tersebut sering tidak dipatuhi oleh pelaksana program. BUMDes sebagai usaha bisnis di sektor publik tidak luput dari kelemahan dalam menata akuntabilitas sumber daya keuangan yang notabene berasal dari keuangan negara. Sayangnya, tingkat akuntabilitas BUMDes berada pada level yang rendah dengan melihat dokumen-dokumen tata kelolanya (Widiastuti et al., 2019).

Penelitian yang dilakukan oleh Irawati dan Martanti (2017) menemukan hubungan yang kuat antara transparansi pengelolaan keuangan oleh BUMDes dengan pertumbuhan aset BUMDes. Dengan laporan keuangan yang akurat, rinci dan informatif, maka BUMDes makin dipercaya oleh pemerintah desa dan masyarakat. Laporan keuangan yang transparan juga mencerminkan usaha yang sungguh-sungguh dari pengelola BUMDes. Dampaknya adalah perkembangan bisnis yang dikelola menjadi semakin prospektif.

Pelatihan penyusunan rencana bisnis mendapatkan sambutan yang cukup positif baik dari peserta maupun pihak pemerintah Kecamatan Lumbir. Hal ini ditandai dengan tingkat kehadiran peserta yang tinggi. Peserta betul-betul mengikuti kegiatan pelatihan dari awal hingga akhir secara antusias. Demikian pula pihak kecamatan memberikan dukungan yang tinggi dengan memfasilitasi koordinasi dengan para kepala desa agar mengirimkan utusan pengelola BUMDes dalam kegiatan pelatihan ini.

Untuk mengukur efektivitas pelatihan, peserta diberikan kuesioner sebelum dan sesudah pelaksanaan pelatihan. Hal ini dimaksudkan untuk mengukur peningkatan pengetahuan pengelola dalam penyusunan dokumen rencana bisnis. Distribusi tingkat pengetahuan peserta tentang penyusunan rencana bisnis dapat dilihat dari Gambar 1.

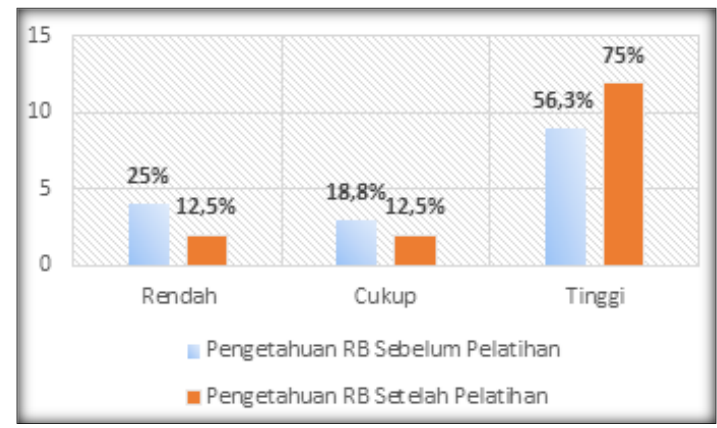

Gambar 1. Distribusi Tingkat Pengetahuan Peserta tentang Rencana Bisnis

Pada Gambar 1 terlihat bahwa pelatihan telah memberikan efek peningkatan tingkat pengetahuan peserta mengenai penyusunan rencana bisnis. Kelompok peserta yang terbagi menjadi tiga golongan menunjukkan bahwa proporsi peserta yang semula memiliki tingkat pengetahuan rendah dan sedang dalam penyusunan rencana bisnis mengalami 
penurunan. Kelompok peserta yang tingkat pengetahuannya tinggi mengalami peningkatan sebanyak $18,7 \%$.

Pengujian secara statistik dengan metode Wilcoxon juga menunjukkan bahwa terdapat perbedaan yang signifikan dalam level pengetahuan peserta sebelum dan sesudah pelatihan $(\mathrm{p}=0,003)$. Artinya, pelatihan telah memberikan efek yang signifikan kepada peningkatan pengetahuan peserta dalam memahami penyusunan rencana bisnis.

Respon peserta terhadap pelatihan juga terlihat positif. Hampir seluruhnya menyatakan optimis dapat menyusun rencana bisnis. Antusiasme ini menjadi sangat penting sebagai modal awal dalam membangun kapasitas manajerial pengelola BUMDes. Dalam proses pelatihan juga nampak keaktifan para peserta untuk menanyakan atau mendiskusikan berbagai permasalahan yang mereka alami dalam mengelola BUMDes.

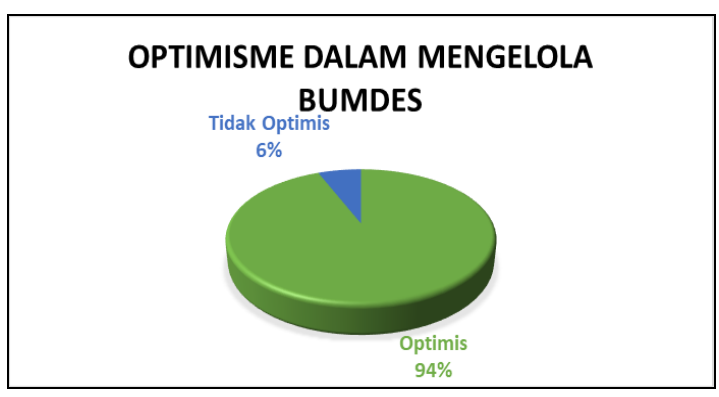

Gambar 2. Optimisme Peserta dalam Mengelola BUMDes

Beberapa permasalahan yang disampaikan peserta pelatihan mencakup:

1. Keterbatasan kemampuan sumber daya pengelola BUMDes.

2. Kepemilikan modal usaha BUMDes yang sangat terbatas.

3. Belum jelasnya sektor usaha yang akan dikembangkan.

4. Dukungan pemerintah desa masih kurang.

Dengan adanya pelatihan penyusunan rencana bisnis, para peserta mendapatkan penguatan pengetahuan dan sikap. Berbagai permasalahan yang dialami oleh pengelola BUMDes pada dasarnya berakar dari ketiadaan analisis rencana bisnis.
Setelah peserta mendapatkan pelatihan mengenai penyusunan rencana bisnis, mereka melaporkan mampu untuk menyusun rencana bisnis. Dokumen rencana bisnis ini memuat visi misi, analisis strategi pasar, analisis strategi produk dan jasa yang akan dikembangkan, dan laporan keuangan BUMDes. Dengan demikian, rencana bisnis dapat menjadi telapedoman bagi BUMDes untuk mengatasi berbagai permasalahan yang dihadapi.

Pentingnya program pelatihan dalam meningkatkan kemampuan pengelola BUMDes juga dilaporkan oleh Zulkarnen (2016). Orientasi pelatihan yang berfokus pada pengembangan manajemen BUMDes sangat dibutuhkan. Hal ini dikarenakan banyak BUMDes yang masih sangat jarang mendapatkan pelatihan manajamen.

Untuk menguatkan dukungan publik kepada BUMDes, Adawiyah (2018) menyarankan adanya keterlibatan masyarakat dalam sosialisasi dan pelatihan mengenai BUMDEs. Hal tersebut dengan alasan bahwa keberhasilan BUMDes tidak hanya ditentukan oleh pengurusnya, tetapi juga tergantung pada partisipasi dan dukungan masyarakat terhadap program-program BUMDes. Masyarakat desa tidak sekedar menjadi pasar potensial bagi produk dan jasa BUMDes. Masyarakat juga dapat berperan dalam mengawasi kerja BUMDes karena bagaimanapun modal BUMDes berasal dari pemerintah.

\section{SIMPULAN}

Berdasarkan hasil kegiatan pengabdian ini dapat disimpulkan bahwa pelatihan dapat meningkatkan tingkat pengetahuan pengelola BUMDes dalam menyusun dokumen rencana bisnis. Pelatihan juga telah meningkatkan optimisme pengelola BUMDes dalam mengelola BUMDes di masa yang akan datang. Pelatihan telah memberikan peningkatan wawasan bagi pengelola BUMDes untuk menyusun rencana bisnis. Dengan bekal pengetahuan ini diharapakan penyusunan rencana bisnis menjadi pedoman strategis untuk pengembangan bisnis BUMDes.

Pasca pelatihan, peserta telah mampu membuat proposal perencanaan BUMDes. 
Namun demikian, masalah utama peserta adalah menggabungkan antara strategi dan perencanaan organisasi dengan penganggaran keuangan. Ketika suatu BUMDes mampu merumuskan visi, misi, tujuan, dan strategi organisasi secara kualitatif, maka mereka sulit membayangkan dari mana sumber dana dan bagaimana proyeksi keuangannya. Sebaliknya, BUMDes yang mampu membuat proyeksi arus kas dengan baik masih kesulitan membuat secara kualitatif. Pengabdian selanjutnya perlu membantu penggabungan perencanaan strategis dan keuangan kepada BUMDes.

\section{UCAPAN TERIMA KASIH}

Kegiatan pengabdian ini dapat terlaksana karena dukungan pendanaan dari Universitas Jenderal Soedirman. Oleh karena itu, tim pengabdi mengucapkan terima kasih kepada UNSOED yang telah memfasilitasi kegiatan pengabdian ini. Terima kasih juga ditujukan kepada Camat dan Staf Kecamatan Lumbir yang telah memfasilitasi tim pengabdi dengan BUMDes di Kecamatan Lumbir.

\section{DAFTAR PUSTAKA}

Adawiyah, R. (2018). Strategi pengembangan Badan Usaha Milik Desa (BUMDes) berbasis aspek modal sosial (Studi pada BUMDes Surya Sejahtera, Desa Kedungturi, Kecamatan Taman, Kabupaten Sidoarjo). Kebijakan dan Manajamen Publik, 6(3), 1-15.

Zulkarnaen, R.M. (2016). Pengembangan potensi ekonomi desa melalui Badan Usaha Milik Desa (Bumdes) Pondok Salam Kabupaten Purwakarta. Dharmakarya: Jurnal Aplikasi Ipteks untuk Masyarakat, 5(1), 1 - 4.

Bovens, M. (2007). Analysing and assessing accountability: A conceptual framework", European Law Journal, 13(4), 447-468.

Dixon, R., Ritchie, J., \& Siwale, J. (2006). Microfinance: Accountability from the frassroots", Accounting Auditing \& Accountability Journal, 19(3), 405 427.
Lodhia, S.K., \& Burritt, R.L. (2004). Public sector accountability failure in emerging economy: Tha case of the National Bank of Fiji", The International Journal of Public Sector Management, 17(4), $345-359$.

Kurniasih, D., \& Wijaya, S.S. (2017). Kegagalan bisnis pemerintah desa: Studi tentang relasi bisnis-pemerintah pada pengelolaan badan usaha milik desa di Kabupaten Banyumas. Journal of Public Sector Innovations, 1(2), 66-72.

Sofyani, H., Atmaja, R., \& Rezki, S.B. (2019). Success factors of villageowned enterprises (BUMDes) performance in Indonesia: An Exploratory Study. Journal of Accounting and Investment, 20(2): 44-58.

Rosyadi, S. (2019). BUMDes butuh penguatan kapasitas manajerial. Suara Merdeka (2 November 2019).

Tempo. (2019). Jokowi sebut 2.188 BUMDes mangkrak. Diunduh dari: https://bisnis.tempo.co/read/1282594/jo kowi-sebut-2-188-bumdes-mangkrak tanggal 11 Desember 2019. 